\title{
Congenital mesoblastic nephroma: Possible prognostic and management value of assessing DNA content
}

\author{
J C Barrantes, C Toyn, K R Muir, S E Parkes, F Raafat, A H Cameron, H B Marsden, \\ J R Mann
}

Department of

Oncology, The

Children's Hospital,

Ladywood,

Birmingham B16 8ET

J C Barrantes

J R Mann

Department of

Pathology, The

Children's Hospital,

Birmingham

C Toyn

F Raafat

The West Midlands

Regional Children's

Tumour Research

Group, The Children's

Hospital, Birmingham

K R Muir

S E Parkes

A H Cameron

The Royal Manchester

Children's Hospital,

Manchester

H B Marsden

Correspondence to:

Dr J R Mann

Accepted for publication

21 November 1990

\begin{abstract}
The case records and pathology of all children with kidney tumours treated in the West Midlands Health Authority Region (WMHAR) from 1957 to 1986 were reviewed. The histology was reviewed by a panel of three paediatric pathologists. Thirteen (6\%) out of 211 cases were considered to have congenital mesoblastic nephroma (CMN). Nine were of the conventional type, three of the atypical cellular type, and one mixed. DNA ploidy was investigated and showed two of the tumours to be aneuploid and nine diploid (tissue was not available in the two other cases). The two aneuploid tumours were of atypical cellular and mixed histology, respectively; the diploid tumours were of the conventional type in eight cases and atypical cellular in one.

The atypical cellular type has been reported to behave more aggressively, but the benefit of additional treatment after surgery to prevent recurrence remains unclear. Measurement of DNA content by flow cytometry, together with histological subclassification, may be useful in selecting patients who will benefit from further treatment after surgery.
\end{abstract}

Congenital mesoblastic nephroma is one of the commonest kidney tumours in infants. It has been associated with a very good prognosis and, in most cases, surgery alone may effect a cure.

It has also been recognised, however, that not all of the cases follow the same course. ${ }^{2-4} \mathrm{~A}$ more aggressive subtype, atypical cellular mesoblastic nephroma with evidence of local recurrence and even distant pulmonary metastases, has been reported in some patients, ${ }^{56}$ but the reasons for the more aggressive behaviour are not known precisely. The existence of a spectrum of tumours covering the whole span of biological behaviour has been proposed ${ }^{78}$ identifying congenital mesoblastic nephroma as a low grade tumour and placing atypical cellular mesoblastic nephroma in the intermediate category. This is based on histological appearances: mesoblastic nephroma appears benign with a leiomyomatous pattern composed of interlacing bundles of spindle cells and few mitotic figures; congenital mesoblastic nephroma is densely cellular, with many mitotic figures. Both patterns can be found in the same tumour, referred to as a mixed tumour. ${ }^{9}$

In trying to explain the histogenesis of these tumours, Snyder et al ${ }^{10}$ proposed a theory using the "two hit" model, described by Knudson." In this model congenital mesoblastic nephroma would occur after a neoplastic mutation in the early stages of embryogenesis, whereas atypical cellular mesoblastic nephroma would develop in the later stages, but before the blastema has undergone metanephric differentiation. In both cases a second mutation would be necessary to produce the malignant transformation. Its origin from premetanephric blastema is supported by an immunohistochemical study by Kumar et al. ${ }^{12}$ Furthermore, Haas et $a l^{13}$ suggested that, on the basis of the highly cellular histological appearances of atypical cellular mesoblastic nephroma, clear cell sarcoma of the kidney (CCSK) may be the malignant counterpart of congenital mesoblastic nephroma and atypical cellular mesoblastic nephroma. More recent studies, however, indicate that this is unlikely. ${ }^{9}$

With a view to investigating the biological characteristics and the possible factors that could influence the decision as to which patients would need further treatment in addition to surgical resection, we undertook review of patients diagnosed as having kidney tumours in the West Midlands Health Authority Region between 1957-1986. As DNA ploidy has shown a correlation with prognosis in Wilms' tumour, ${ }^{14} 15$ which explains its aggressive behaviour in some patients, we also performed flow cytometry wherever possible.

The objectives of the present study were:

(1) To review the incidence, clinical presentation, and outcome of patients with congenital mesoblastic nephroma in the West Midlands over a 30 year period.

(2) To determine if there is any difference in DNA ploidy between typical congenital mesoblastic nephroma and atypical cellular mesoblastic nephroma and any possible implications for the biological nature and behaviour of the subgroups. 
Methods

We reviewed the case records of children aged 0-14 years, resident in the West Midlands Health Authority Region (average childhood population 1.17 million) who were diagnosed as having kidney tumours between 1957 and 1986.

The cases were identified from the West Midlands Regional Children's Tumour Research Group. Data are held on all cases of childhood cancer (0-14 years) in the WMHAR from 1957, based on the records of the Birmingham and West Midlands Regional Cancer Registry, the Children's Cancer Research Group, Oxford, and the files of the Oncology and Histopathology Departments of The Children's Hospital, Birmingham. Clinical and histological staging of these tumours were carried out following the same staging system as for Wilms' tumour, proposed after the National Wilms' Tumour Study (NWTS-2). ${ }^{16}$ The available pathology material was reviewed by a panel of three paediatric histopathologists.

Sections $30 \mathrm{~mm}$ thick from paraffin wax embedded pathological material were obtained and prepared for flow cytometry, according to the method described by Hedley, ${ }^{17}$ with minor modifications.

The nuclear DNA content of 20000 cells was measured using a Becton Dickinson FACS 440 flow cytometer with an excitation wavelength of $448 \mathrm{~nm}$, emission filter of $590 \mathrm{~nm} \mathrm{LP}$, and laser power of 0.2 watts. Normal kidney tissue was used as an external control, and stromal cells from each sample were taken as the normal internal standard.

The DNA content was considered to be diploid when only one $\mathrm{g} 0 / \mathrm{g} 1$ peak was present in the histogram and aneuploid when two or more $\mathrm{g} 0 / \mathrm{gl}$ peaks were obtained. S phase (synthetic phase) was identified as the percentage of cells lying between the g0/g1 and the $\mathrm{g} 2 \mathrm{M}$ peaks. The DNA index (DI) represented the ratio of the modal channel number of the aneuploid $\mathrm{g} 0 / \mathrm{gl}$ peak to the modal channel number of the diploid $\mathrm{g} 0 / \mathrm{g} 1$ peak.

The proliferation index (PI) was obtained by the sum of the cells in S phase and g2M. The coefficient of variation (CV) was obtained using the resident Becton Dickinson software. Evaluable information for DNA ploidy was obtained in 11 of the 13 patients.

\section{Results}

From a total of 211 kidney tumours diagnosed in the study period, $13(6.2 \%)$ cases of congenital mesoblastic nephroma were found. Table 1 shows the principal characteristics of the whole group. Although most children (eight of 13) presented during infancy, two were over 1 year of age. There were eight males and five females, ratio 1·6:1.

The most common presenting features were abdominal distension and mass. Only one patient had a congenital abnormality, presenting with a congenital mesoblastic nephroma in the left side of a horse-shoe kidney.

All patients had surgery as the principal treatment. Eleven had a nephrectomy, one had the tumour excised from a horse-shoe kidney, and one with a well localised tumour had a partial nephrectomy. In seven cases surgery was the only treatment (including the child with the horse-shoe kidney). Three of the patients received chemotherapy after surgery, two had radiotherapy to the tumour bed, and one had both.

The tumours were stage $I$ in four patients and stage II in eight, because of local spread through the capsule into the perirenal tissue. One patient (case 6) had the primary tumour confined to the kidney, but malignant cells were suspected in the bone marrow, so he was treated with chemotherapy and radiotherapy, following the Medical Research Council Wilms' tumour protocol. Histological review showed that nine had congenital mesoblastic nephroma of the conventional type, three had atypical cellular mesoblastic nephroma, and one had a mixed tumour.

Analysis of DNA content was possible in 11 cases, nine of which were diploid (fig 1) and two aneuploid (fig 2). The two aneuploid tumours were of cellular and mixed types, respectively. The results of the DNA studies are shown in table 2.

The PI was very high in one patient (case 9) (table 2), mildly increased in another (case 1) (table 2), and the remainder of the patients had a PI of $<10 \%$. The DI of the aneuploid tumours was 1.4 and 1.3 , respectively. The median CV of the whole group was 8.3 with a range of 4.7-10. The histograms of some of our patients exhibited considerable variation in the position of the $\mathrm{g} 0 / \mathrm{g} 1$ and $\mathrm{g} 2 \mathrm{M}$ peaks in otherwise normal histograms. This effect has been

Table 1 Congenital mesoblastic nephroma: general characteristics

\begin{tabular}{|c|c|c|c|c|c|c|c|c|}
\hline $\begin{array}{l}\text { Case } \\
\text { No }\end{array}$ & $\begin{array}{l}\text { Age } \\
(\boldsymbol{m})\end{array}$ & Sex & Side & Stage & $\begin{array}{l}\text { Histological } \\
\text { type }\end{array}$ & Treatment ${ }^{\star}$ & Outcome & $\begin{array}{l}\text { Follow up } \\
\text { (years) }\end{array}$ \\
\hline $\begin{array}{r}1 \\
3 \\
4 \\
5 \\
8 \\
9 \\
10 \\
11 \\
13 \\
6 \\
7 \\
12 \\
2\end{array}$ & $\begin{array}{l}\text { NB } \\
\text { NB } \\
\text { NB } \\
\text { NB } \\
\text { NB } \\
13 \\
\text { NB } \\
\text { NB } \\
\text { NB } \\
19 \\
1 \\
7 \\
3\end{array}$ & $\begin{array}{l}\mathbf{M} \\
\mathbf{M} \\
\mathbf{F} \\
\mathbf{M} \\
\mathbf{M} \\
\mathbf{F} \\
\mathbf{M} \\
\mathbf{F} \\
\mathbf{F} \\
\mathbf{M} \\
\mathbf{M} \\
\mathbf{F} \\
\mathbf{M}\end{array}$ & $\begin{array}{l}\text { L } \\
\text { L } \\
\text { R } \\
\text { L } \\
\text { R } \\
\text { L } \\
\text { L } \\
\text { L } \\
\text { L } \\
\text { R } \\
\text { L } \\
\text { L } \\
\text { R }\end{array}$ & $\begin{array}{l}2 \\
1 \\
2 \\
2 \\
2 \\
2 \\
2 \\
2 \\
1 \\
? 4 \dagger \\
1 \\
1 \\
2\end{array}$ & $\begin{array}{l}\text { CMN } \\
\text { CMN } \\
\text { CMN } \\
\text { CMN } \\
\text { CMN } \\
\text { CMN } \\
\text { CMN } \\
\text { CMN } \\
\text { CMN } \\
\text { ACMN } \\
\text { ACMN } \\
\text { ACMN } \\
\text { Mixed }\end{array}$ & $\begin{array}{l}\text { RT } \\
\text { None } \\
\text { None } \\
\text { None } \\
\text { None } \\
\text { CT } \\
\text { None } \\
\text { None } \\
\text { None } \\
\text { CT; RT } \\
\text { CT } \\
\text { CT } \\
\text { RT }\end{array}$ & $\begin{array}{l}\text { D } \\
\text { A } \\
\text { D } \\
\text { A } \\
\text { A } \\
\text { A } \\
\text { A } \\
\text { A } \\
\text { A } \\
\text { A } \\
\text { A } \\
\text { A } \\
\text { A }\end{array}$ & $\begin{array}{c}0 \cdot 75 \\
14 \cdot 5 \\
5 \text { days } \\
11 \cdot 6 \\
5 \cdot 8 \\
5 \\
0 \cdot 4 \\
1 \cdot 4 \\
2 \cdot 8 \\
8 \cdot 3 \\
5 \cdot 8 \\
3 \cdot 3 \\
25\end{array}$ \\
\hline
\end{tabular}

*In addition to nephrectomy.

†Bone marrow: suspected malignant cells.

$\mathrm{NB}=$ newborn; $\mathrm{CT}=$ chemotherapy; $\mathrm{RT}=$ radiotherapy; $\mathrm{A}=$ alive $\mathbf{D}=$ dead. 
Figure 1 Diploid DNA content in a conventional mesoblastic nephroma.

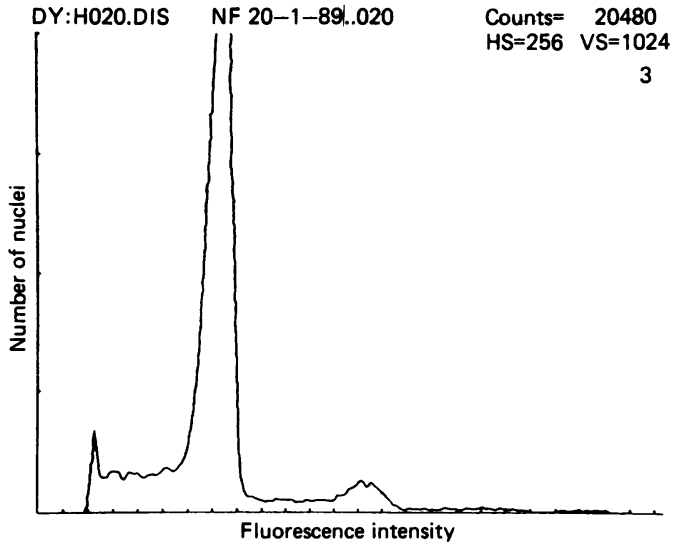

described as a consequence of the fixation of the tissue in the paraffin wax blocks. ${ }^{18}$

Only two patients out of 13 died, one of them as a consequence of a postoperative complication four days after surgery. The other child died nine months after the nephrectomy with uncontrollable ascites and clinical evidence of progressive disease, although neither histology nor cytology was obtained at the time of this probable recurrence and a post mortem examination was not performed.

Eleven patients were still alive and well at follow up of between one year and five months to 25 years (median five years nine months).

\section{Discussion}

In our 30 year series congenital mesoblastic nephroma represented $6.5 \%$ of all renal tumours. This incidence seems to be higher than has previously been reported by the National Wilms' Tumor Study ${ }^{19}$ and in England (H B Marsden, personal communication).

There were no familial cases, nor any suggestion of predisposing factors in our group. Only one patient was found to have a congenital abnormality (horse-shoe kidney) which correlates with the findings in other series. ${ }^{20}$

We found an almost equal male:female distribution with 5:4 for the conventional congenital mesoblastic nephroma group and 2:1 for the atypical cellular mesoblastic group. It is interesting to note that two of the patients were over 1 year old at presentation, one of them with a congenital mesoblastic nephroma of the conventional type. This patient also had the

Figure 2 Aneuploid tumour in atypical cellular mesoblastic nephroma showing the second peak with the hyperdiploid DNA content.

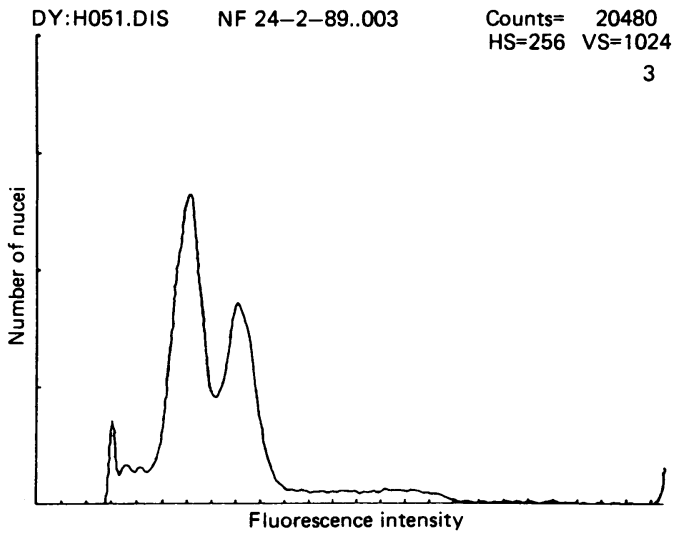

Table 2 DNA studies of congenital mesoblastic nephroma (CMN)

\begin{tabular}{rllll}
\hline $\begin{array}{l}\text { Case } \\
\text { No }\end{array}$ & $\begin{array}{l}\text { Histological } \\
\text { type }\end{array}$ & Ploidy & DI & PI \\
\hline 1 & CMN & D & & 16.0 \\
3 & CMN & D & & $<1$ \\
4 & CMN & D & & $3 \cdot 4$ \\
5 & CMN & D & & $6 \cdot 9$ \\
8 & CMN & D & & $51 \cdot 4$ \\
9 & CMN & D & & 8.5 \\
10 & CMN & D & & $5 \cdot 0$ \\
11 & CMN & D & & $3 \cdot 6$ \\
13 & ACN & D & & \\
6 & ACMN & A & 1.4 & \\
7 & ACMN & ACMN & 1.3 & \\
12 & Mixed & A & \\
2 & &
\end{tabular}

DI $=$ DNA index; PI $=$ proliferative index; $D=$ diploid; $\mathrm{A}=$ aneuploid.

highest PI value in the DNA studies (case 9) (table 2) and was one of the two with congenital mesoblastic nephroma that received additional treatment after surgery. He remained well with no evidence of recurrence at five year follow up.

Congenital mesoblastic nephroma enjoys an excellent prognosis and, as several studies have shown, patients do very well with surgery alone. ${ }^{12021}$ Beckwith first postulated, ${ }^{7}$ later supported by- others ${ }^{520}$ certain characteristics which might indicate the need for additional treatment after surgery. It was suggested that patients over three months of age, who have residual disease and whose tumours show atypical features indicating more aggressive behaviour, may benefit from more extensive treatment.

What makes this tumour vary in its biological behaviour is unknown. There are differences in the macroscopic and histological appearances which have been well documented, ${ }^{5}$ showing more aggressive features such as fleshy areas, haemorrhage and necrosis, hypercellularity and high mitotic index. It is not as yet possible on the basis of these characteristics, however, to predict which tumours will behave more agggressively and which will recur or metastasise. Furthermore, despite recommendations for the use of chemotherapy or radiotherapy, or both, in some cases and the fact that some tumours have recurred after inadequate or no chemotherapy ${ }^{2}$ while others have achieved complete remission with chemotherapy, ${ }^{20}$ the role of adjuvant treatment is not clear. Whether congenital mesoblastic nephroma and its variant respond to chemotherapy or radiotherapy has not been convincingly proved.

As DNA ploidy has shown a good correlation with prognosis in Wilms' tumour ${ }^{14}$ we decided to study the DNA content in congenital mesoblastic nephroma. Two of the tumours were clearly aneuploid, showing two g0/g1 peaks (fig 2). The histology for these was cellular and mixed, respectively. Of the other two cases of atypical cellular mesoblastic nephroma, one had inadequate material for study and the other was diploid. Unfortunately, the number of patients was too small to reach any definite conclusion. It is possible to speculate, however, that an increase in the DNA content may produce changes in the biology of the cellular variant. 
When we examined the outcome of the patients with the atypical cellular mesoblastic nephroma variant, we found that all four were alive with no evidence of recurrence, but it is notable that all received further treatment in addition to surgery (table 1 ).

If the changes in DNA reflect a highly proliferative tumour with more aggressive behaviour, but at the same time better response to treatment, as has been proposed for neuroblastoma ${ }^{22}{ }^{23}$ and acute lymphoblastic leukaemia, ${ }^{24}$ then aneuploidy would not necessarily represent a poor prognostic feature for congenital mesoblastic nephroma, as long as appropriate treatment in addition to surgery were given. If this were so, flow cytometry could become an important tool in defining which patients would benefit from other methods of treatment, and even to predict which could sustain recurrence or develop metastases.

Pettinato et al performed flow cytometric studies in three patients with congenital mesoblastic nephroma, one with a conventional type, one with atypical cellular mesoblastic nephroma, and on both components of a mixed tumour. ${ }^{25}$ The conventional and atypical cellular mesoblastic nephroma types showed diploid DNA content, but the cellular area of the mixed tumour was aneuploid. He concluded that cytogenetics and ploidy analysis did not seem to be beneficial in the selection of patients who will need additional treatment, although the number of cases included in his analysis was too small to define their role accurately. It is interesting that his findings were similar to ours.

One patient in our series with congenital mesoblastic nephroma of the conventional type and no adverse features died apparently with progressive disease. He was initially diagnosed as having Wilms' tumour and received radiotherapy to the tumour bed. He subsequently developed ascites and finally died nine months after diagnosis. Unfortunately there was no histological confirmation of the recurrence and a post mortem examination was not carried out. This is a most interesting case and could represent a patient with an aggressive congenital mesoblastic nephroma of the conventional type with fatal outcome. Without pathological evidence, however, this must remain speculation.

Our series illustrates some of the characteristics of congenital mesoblastic nephroma and its variant, atypical cellular mesoblastic nephroma. It is clear that most children with this tumour will do well with surgery alone. For the small proportion of patients whose tumours show more aggressive behaviour it seems logical to use additional chemotherapy or radiotherapy, or both. Whether these two modalities of treatment are effective in congenital mesoblastic nephroma is not completely clear. Perhaps it is in this area that flow cytometry might be useful in the selection of patients who will need further treatment to achieve a better response. Studies of larger numbers of patients with congenital mesoblastic nephroma are required to clarify this. We thank the West Midlands Regional Health Authority, the
Special Trustees of the Former United Birmingham Hospitals, and the British Council for financial support; Ms C Roginsky for and the British Council for financial support; Ms CRoginsky for help with access to data in the Birmingham and West Midlands Regional Cancer Registry; and Dr G J Draper and Mr C A
Stiller for access to data held by the Children's Cancer Research Group.

Thanks are also due to Mrs $\mathrm{K}$ Smith for technical support and to numerous medical records officers, consultant colleagues, and general practitioners for access to patients' medical records and histopathological material.

1 Howell CA, Othersen HB, Kiviat NE, et al. Therapy and outcome in 51 children with congenital mesoblastic nephroma. A report of the NWTS. J Pediatr Surg 1982; 17:826-31.

2 Joshi VV, Kay S, Milsten R, et al. Congenital mesoblastic nephroma in infancy. Report of a case with unusual clinical behavior. Am J Clin Pathol 1973;60:811-6.

$3 \mathrm{Fu}$ YS, Kay S. Congenital mesoblastic nephroma and its recurrence. Arch Pathol 1973;96:66-70.

4 Walker D, Richard GA. Fetal hamartoma of the kidney. Recurrence and death of the patient. J Urol 1973;110: 352-3.

5 Joshi VV, Kasznica J, Walters T. Atypical mesoblastic nephroma: pathological characteristics of a potentially
aggressive variant of congenital mesoblastic nephroma. aggressive variant of congenital meso
Arch Pathol Lab Med 1986;110:100-6.

6 Steinfield AD, Crowley CA, O'Shea PA, Tefft M. Recurrent and metastatic mesoblastic nephroma in infancy. J Clin Oncol 1984;2:956-60.

7 Beckwith JB. Mesenchymal renal neoplasm of infancy revisited. J Pediatr Surg 1974;9:803-5.

8 Gonzalez-Crussi F, Sotelo-Avila C, Kidd JH. Mesenchymal renal tumours in infancy: a reappraisal. Hum Pathol 1981; 12:78-85.

9 Marsden HB, Newton WA. New look at mesoblastic nephroma. J Clin Pathol 1986;39:508-13.

10 Snyder HM, Lack EE, Chetty-Bektaviziam A, et al. Congenital mesoblastic nephroma: relationship to other renal genital mesoblastic nephroma: relationship
tumors in infancy. $J$ Urol 1981;126:513-6.

11 Knudson AG Jr, Strong LC. Mutation and cancer: a model for Wilms' tumor of the kidney. JNCI 1972;48:313-24.

12 Kumar S, Carr T, Marsden HB, Calabuig-Crespo MC. Study of childhood renal tumours, using antisera to fibronectin, laminin and epithelial membrane antigen $J$ Clin Pathol 1986;39:51-7.

13 Haas JE, Bonadio JF, Beckwith JB. Clear cell sarcoma of the kidney with emphasis on ultrastructural studies. Cancer 1984;54:2978-87.

14 Douglas EC, Look T, Webber B, et al. Hyperdiploidy and chromosomal rearrangements define the anaplastic variant of Wilms' tumor. J Clin Oncol 1986;4:975-81.

15 Kumar S, Marsden HB, Cowan RA, Barnes JM. Prognostic relevance of DNA content in childhood renal tumours. $B r$ relevance of DNA content
$J$ Cancer 1989;59:291-5.

16 Forewell VT, D'Angio GT, Breslow N, Norkool P. Retrospective validation of a new staging system for Wilms' spective validation of a new staging syst
tumor. Cancer Clin Trials 1981;4:167-71.

17 Hedley DW, Friedlander ML, Taylor IW, et al. Method for analysis of cellular DNA content of paraffin-embedded pathological material using flow cytometry. $J$ Histochem Cytochem 1983;31:1333-5.

18 Frierson HF. Flow cytometric analysis of ploidy in solid neoplasms: Comparison of fresh tissues with formalinfixed paraffin embedded specimens. Hum Pathol 1988;19. $290-4$.

19 D'Angio GD, Evans A, Breslow N, et al. The treatment of Wilms' tumor: Results of the second National Wilms' Tumor Study. Cancer 1981;47:2302-11.

20 Chan HS, Cheng MY, Maucer K, et al. Congenital mesoblastic nephroma: a clinicoradiologic study of 17 cases representing the pathological spectrum of the disease. representing the pathologica

21 Bolande RP. Congenital mesoblastic nephroma in infancy. Perspect Pediatr Pathol 1973;1:227-50.

22 Look T, Hayes A, Nitscht R, et al. Cellular DNA content as a predictor of response to chemotherapy in infants with unresectable neuroblastoma. N Engl J Med 1984;311 231-5.

23 Oppedal BR, Storm-Mathisen I, Lie SO, Brandtzaeg P Prognostic factors in neuroblastoma: clinical, histopathoogical and immunohistochemical features and DNA ploidy in relation to prognosis. Cancer 1988;62:772-80.

24 Tsurusawa M, Katono NM, Kawai S, Fugimoto T, Moede M. Prognostic implications of cellular DNA content in acute lymphoblastic leukemia. Am J Ped Hematol Oncol 1988;10:75-80.

25 Pettinato G, Manivel JC, Wick MR, Dehner LP. Classical and cellular (atypical) congenital mesoblastic nephroma: chemical and flow cytometric study. Hum Pathol 1989; 20:682-90. 